\title{
ONTOLOGY DRIVEN KNOWLEDGE MAP For Enhancing Business Process ReEngineering
}

\author{
Mahdi alhaji Musa, Mohd Shahizan Othman, Waleed Mugaheed Al-Rahimi \\ Department of Information System, Universiti Teknologi Malaysia, Johor Bahru, \\ Malaysia
}

\begin{abstract}
It has been a constant human desire to be dissatisfied with the status quo as there is always need to improve upon the way business is being done. As a result, Business process reengineering is introduced into organization in order to overcome these challenges of inefficiencies and high running cost. A lot of problems were encountered during the process of reengineering programmes. One of many factors that are identified as the possible reason for the failures in most business process reengineering is the lack of giving much emphasis on the knowledge available within the environment in which the business process is taking place. In this paper therefore we propose a methodology that addresses this issue through the use knowledge source map and formal organizational ontology. The organization and business process are model together to provides most efficient way of utilizing the knowledge in the organization in the event of business process reengineering.
\end{abstract}

\section{KEYWORDS}

Business process reengineering, knowledge map, organizational modeling.

\section{INTRODUCTION}

It has been a constant human desire to be dissatisfied with the status quo we always need to improve upon the way we do things. It is this very desire which has seen the humankind develops from being cave-dwelling food gatherers to the present- day creators of megacities and a sprawling industrial civilization. There hasn't been a single aspect of the human story which has not been affected by this natural urge to grow and change into something better than it was before [1].

It is this urge which has brought about a sea change in which business is carried out in the modern world. Technology has become the very bedrock on which the multimillion dollar businesses are run and information technology has become a magician's wand which keeps the wheel of global economy turning [2].

In last few years, one such business paradigm which has gained a lot of traction in recent years is business process re-engineering (BPR). BPR is define as "fundamentally rethinking the radical redesign of business processes to achieve dramatic improvements in critical, contemporary measures of performance such as cost, quality, service and speed." Whole lot of organizations both private and public including Universities are either undergoing the BPR exercise or are looking at awe with the kind of results their peers and competitors have been able to achieve as a result of BPR.[3]

DOI : $10.5121 /$ cseij.2013.3602 
This sudden rush for BPR is not something which has happened out of the blue, but rather is a culmination of a chain of events which started with the assault by Japanese auto companies in the US market, which gave rise to business paradigms like TQM, and rapid improvements in the information technology and automation techniques over the years[4].

One of the factors influencing a successful BPR is understanding the environment within which the business process exists and of automating the identification of the inefficiencies and inconsistencies in the business process. This lack of understanding of the environment suggests the need for the integration of knowledge management models and techniques. One such knowledge management technique that could be relevant is knowledge mapping, as knowledge maps can be used for several purposes, including finding sources of knowledge or opportunities for knowledge creation, identifying expertise and increasing knowledge-sharing, and helping to determine the knowledge competencies that exist within an organization and how they interact.[5]

Firms have been reengineering various business functions for years, ranging from customer relationship management to order fulfilment, and from assembly lines to logistics. Anecdotal evidence suggests that many organizations gained benefits from BPR projects[6] For instance, the CIGNA Corporation successfully completed a number of BPR projects and realized savings of $\$ 100$ million by improving its customer service and reducing operating expenses [6]. Similarly, reengineering the accounts payable process at the Ford Motor Company increased the speed of payments and improved company relations with suppliers [7]. Arguably, some BPR projects fail to meet expectations.

This much publicized initial success stories of BPR led to wide acceptance of the concept and as a result several organizations decide to venture into it. A study by CSC/index reported that $72 \%$ of the 224 firms it surveyed had initiated BPR programmes.[8]. Another study confirmed that $85 \%$ of the respondents to a survey conducted in 2005 regarding BPR have initiated the programmes.

Unfortunately, even though a lot of organizations embraced the concept of this BPR programmes, but only few of them immerge successful in their effort. Study indicates that many top management of organizations are disappointed with the result of the programme.[9]. And that the failure rates are as high as 70\% (Lila Rao, 2012). The initiation and diffusion of the BPR like most of the management concept follows a S-shaped curve. When this concept was first introduce in early 90s there was an overwhelming success and large scale acceptance. After spate of failures and difficult nature in implementation, the initiatives become serious challenges to both the researchers and practitioners[5].

\section{RELATED WORK}

This section presents the literature review of the theoretical concepts involved in the business process re-engineering (BPR). It begins by defining and analyzing the nature and role of business process re-engineering in the modern organisation. This is followed by a discussion of the environmental issues associated with business process re-engineering initiative indicating the importance of several supporting concepts such as organizational knowledge, organizational modeling, considering the environment when embarking on BPR programme, selecting best methodology for BPR using knowledge mapping, and selecting appropriate tools for modeling both BPR and environment. Finally, the criticisms and contradictions associated with the concept of business process re-engineering are presented. 


\subsection{BuSINESS Process ReENGINEERING}

Business-process reengineering (BPR) is considered by many to have "had its day," and scholars such as Hansen (Foster, 1994) have stated that BPR is a misnomer: that reengineering does not exist because business systems were never engineered in the first place but simply developed. Others, such as [10] argue that BPR is a fascinating concept that has the potential to "save" a "failing" company and lead it to survival and growth, with [11] and [12]reporting empirical evidence to substantiate the "value" of BPR.

The environment within which businesses conduct themselves is going through rapid and farreaching changes, with companies restructuring themselves to fit competitive "lean and agile" profiles. As a result, they are analyzing their business processes and scrutinizing ways to make their systems more streamlined and competitive [13]

A variety of definitions of BPR have been proposed in the literature [14]; Davenport and Short, [13] but the one cited as being normative comes from [15] and was presented in their seminal book Reengineering the Corporation: A Manifesto for Business Revolution. They define BPR as "fundamentally rethinking the radical re-design of business processes to achieve dramatic improvements in critical, contemporary measures of performance such as cost, quality, service and speed."

Business-process reengineering is a vehicle with which to improve performance through radically redesigning strategic, tactical, and operational processes, together with the procedures, policies, structures, and infrastructure that supports them. Business-process reengineering is cited as offering organizations a whole host of benefits (strategic, tactical, and operational) with differing natures (financial, nonfinancial, and intangible). Such benefits include improved quality of products, processes, flexibility gains, reduced costs, and improved efficiency and effectiveness. But unless environment is put into consideration the programmes will remain unsuccessful.

\subsection{ORGANIZATIONAL KNOWLEDGE}

Knowing is defined as how knowledge works in a business system and is important in understanding how tacit knowledge is used in the [16]. Research in modelling processes suggests that organizational processes should be modelled based on four perspectives - functional, behavioral, informational and [17]. The functional perspective describes the tasks performed, why (i.e. what goals the tasks are achieving) and the informational objects required. The organizational perspective focuses on and with what resources the tasks are performed). This perspective considers the roles, actors and other resources that are deployed. The behavioural perspective focuses on when tasks are performed and how (e.g. the sequencing of tasks). These four perspectives provide the who, what, where, why, when and how of the process in an organization.

\subsection{KNOWLEDGE MAP}

A map is a drawing that reveals physical and/or abstract relationships for places or objects of interest. Throughout human history, people have been creating physical maps, such as cave paintings, atlases, and more recently satellite scans and three-dimensional computer visualization. Examples of abstract maps include Concept Map for learning objects [19] and Mind Map for improving memorization [20]

A knowledge map is a knowledge representation that reveals the underlying relationships of the knowledge sources, using a map metaphor for spatial display. For example, a knowledge map for 
news articles could highlight the current major news topics and their relationships by using blocks to represent key concepts and possibly using lines to represent relationships[20]

Table 1: Mapping techniques for the knowledge map context

\begin{tabular}{|l|l|}
\hline \multicolumn{1}{|c|}{ Simple Mapping Techniques } & \multicolumn{1}{c|}{$\begin{array}{c}\text { Complex Mapping } \\
\text { Techniques }\end{array}$} \\
\hline Mind mapping & Concept maps \\
\hline Clustering & Cause maps, \\
\hline Matrices or portfolio diagrams & $\begin{array}{l}\text { Concentric circles or Venn } \\
\text { diagrams }\end{array}$ \\
\hline Fishbone graphs & $\begin{array}{l}\text { Metaphoric maps (e.g., a } \\
\text { house, a balance, a compass, } \\
\text { or a park) }\end{array}$ \\
\hline $\begin{array}{l}\text { Cartesian and polar co-ordinate } \\
\text { systems }\end{array}$ & Process charts or flow charts \\
\hline Pyramids & Spider web graphs \\
\hline Hierarchic trees & Decision trees \\
\hline Geographic maps & $\begin{array}{l}\text { 3D-environments (e.g., } \\
\text { globes, landscapes) }\end{array}$ \\
\hline
\end{tabular}

The individual items of knowledge included in such a map can be text, stories, graphics, models, or numbers. Knowledge mapping is defined as the process of associating items of information or knowledge (preferably visually) in such a way that the mapping itself also creates additional knowledge." types of knowledge maps that can be used in a corporate context. Below we provide such a distinction: [20]

\subsection{ORgANiZATIONAL MODELING}

Several organizational modelling paradigms have been proposed, each with its own focus. The review of the existing organizational modelling literature shows that the major emphasis is on modelling the roles and the tasks performed Several organizational modelling techniques exist, for example, AALADIN, Agent/Group/Role (AGR), MOISE+, Agile Integration Modeling Language (AIML), Enterprise Ontology, each of which focuses on a specific aspect of an organization. AALADINand AGR focus onmodelling the structural aspect of the organization (e.g. groups, roles and agents). MOISE+focuses on the functional aspect of the organization (e.g. goals, plans andmission) [17]. AIML focuses on goals, roles, agents, tasks and interactions [21]. An enterprise ontology considers an enterprise model to be a computational representation of processes, information, resources, people, behaviour, goals and constraints [22] and therefore can be considered to be an encapsulation of the other modelling techniques.

\section{Methodology}

This paper used design science approach to develop the artifact. In this case the artifact is a methodology that will enhance the business process reengineering in an organization. The method will consider the overall environment and model together with the business process. The researcher will integrate some existing techniques currently used in modeling business process like knowledge map, organizational ontology and some business process diagrams. The process consist of 7 steps, the details of each steps will be discussed in the following sections. 
Computer Science \& Engineering: An International Journal (CSEIJ), Vol. 3, No. 6, December 2013

\subsection{DEVELOP A HIGHLY ORGANIZE ORGANIZATIONAL KNOWLEDGE MAP}

The first step in designing the methodology will be developing an organizational map. The ontology mapping represents the organizational knowledge which provides the means to understand the relationships between organizational goals, sub-goals, business processes, tasks, subtasks, resources and decision makers (e.g. groups, actors). It helps to identify the business processes and the tasks and subtasks required to carry out each of these processes. It can also be used to identify which roles and/or groups are carrying out particular subtasks and the resources that are being produced and consumed during the execution of these subtasks. In figure1 below it represent the knowledge map of the organization. The map describes the details relationship between various stakeholders of the organization

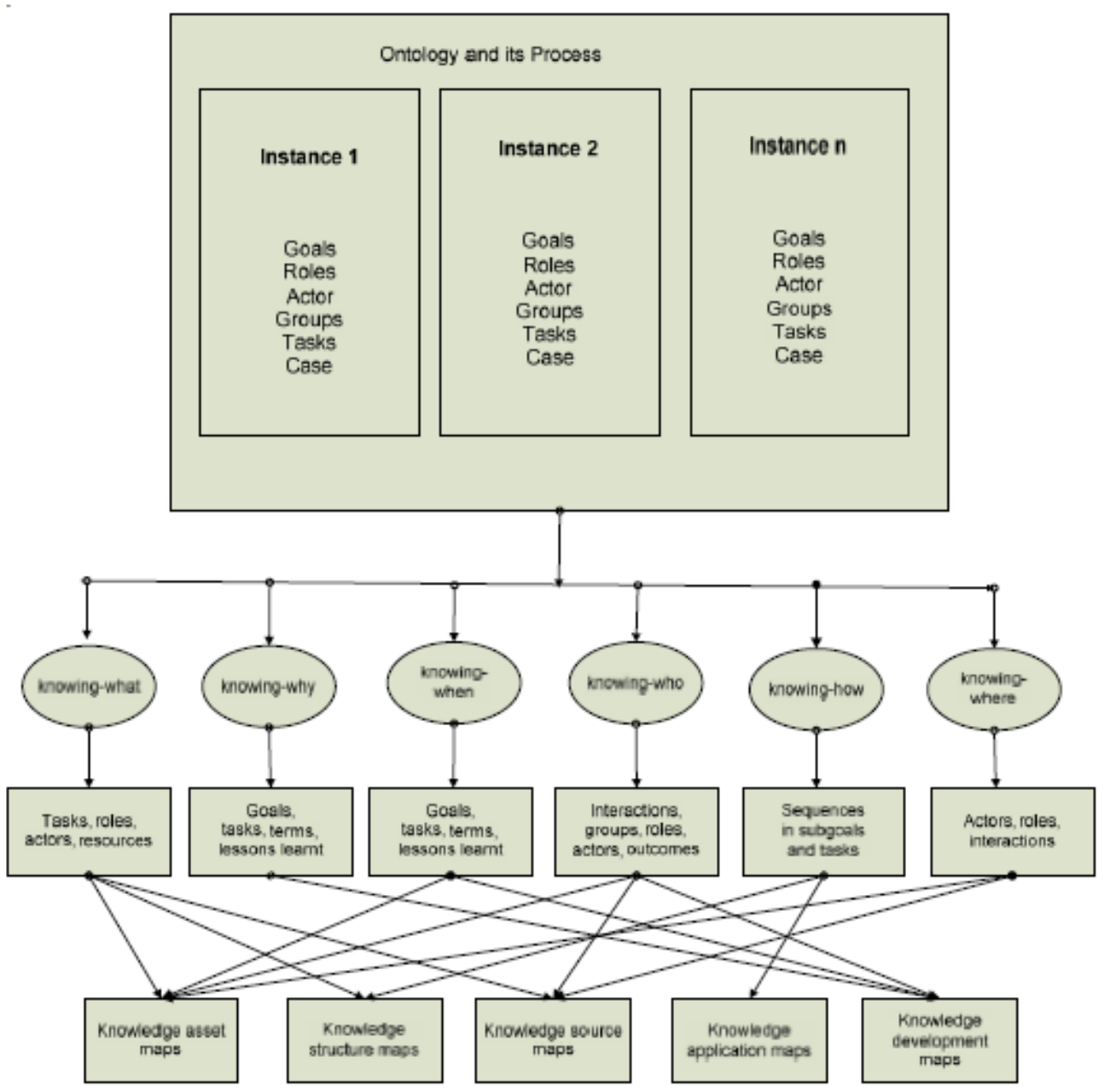

Figure1. Analyse the knowledge map to check for inconsistencies

After carefully developing the organizational knowledge map, the next step is to analyse the map in order to check for inconsistencies. This including checking the know-what for example and making sure a particular actor knows where a particular resources is located in the knowledge asset map. And in the know-who aspect, is by making sure that groups and actors knows which and where they can interacts to get what they need for a particular task assigned to them. If there 
Computer Science \& Engineering: An International Journal (CSEIJ), Vol. 3, No. 6, December 2013

are any inconsistencies in the map we have to the re-address the issues and make sure that the map is good enough based on the ontology of that organization.

\subsection{DeVelop KnOWledge Source/Structure Map For The Organization}

After building the general organizational map, there is a need to develop a specific source and structure map for a particular case. This maps will allows us to know the relationship between a specific actor and his corresponding roles. The maps will help also in achieving specific organizational sub-goals. It will explain the interaction in deferent types of knowledge sharing forums that exist in the organization. The maps are usually developed through the documentation made available in the organization and from series of interview from the employee of that organization.

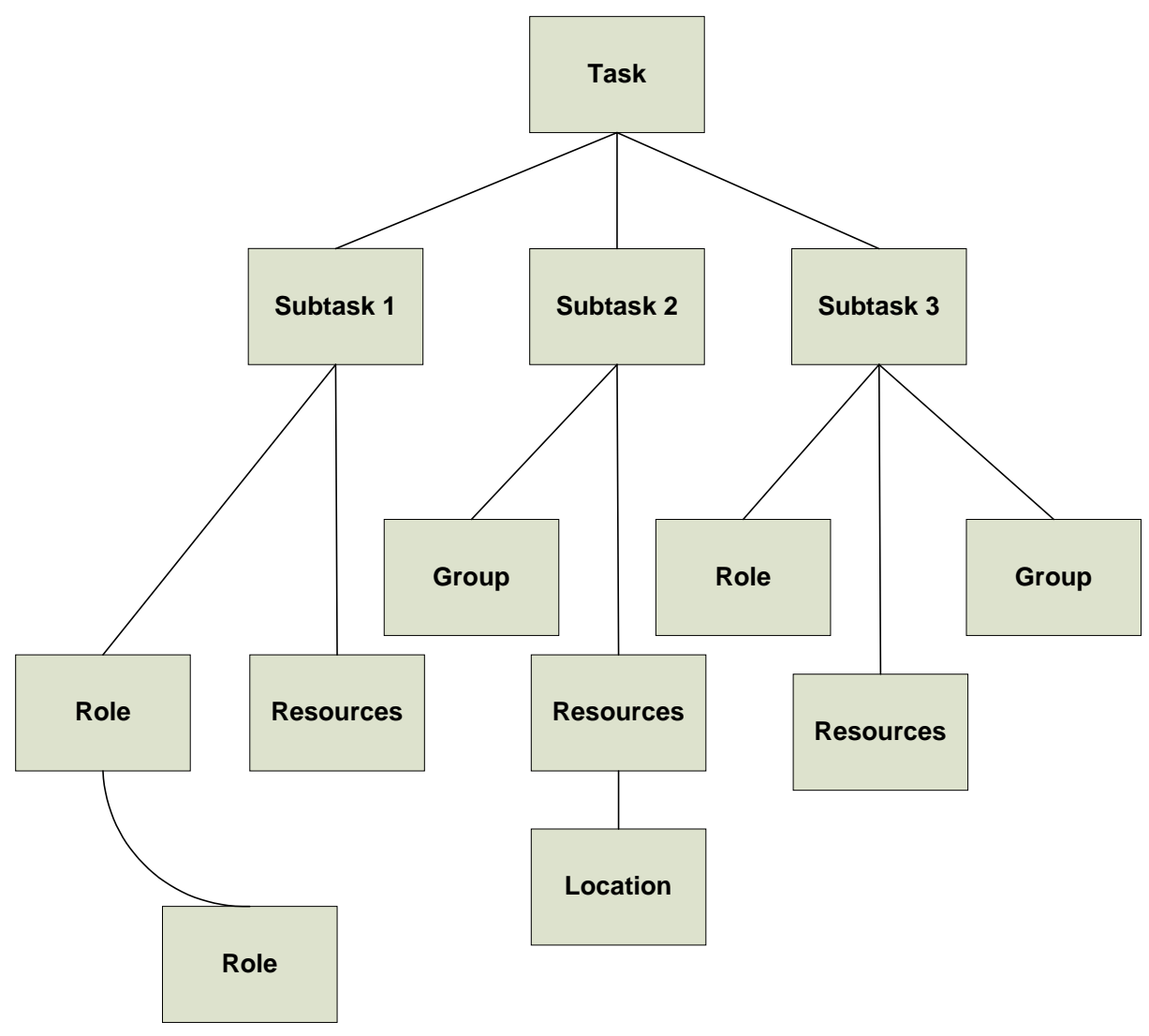

Figure2. Knowledge map development

\subsection{Analyses The KnOWledge Source MaP}

This map normally provides us with very important tools for identifying some possible courses of mismatch in the organizational ontology. And also will provides us with information on lapses in business process for that organization. The violation of certain relationship example the relationship that exists between the actor and his role can hinders consistency of the business process in the organization. If a doctor violate his role with respect to a nurse this will deter the consistencies as such will affect the business process re-engineering. 
Computer Science \& Engineering: An International Journal (CSEIJ), Vol. 3, No. 6, December 2013

\subsection{DEVELOP/AdAPT ORganizational ONTOLOGY USING ThE KNOWLEDGE MAP}

Organizational ontology is proposed for representing 'who does what' and 'who knows what' in an organization. The ontology provides a knowledge perspective of an organization, as it helps in representing knowledge that is embedded in the actual practices (i.e. the cases) of an organization. Using the knowledge map already created, the next step is to develop organizational ontology.

\subsection{Identify The Business Process In The Organization To Be ReEngineered}

In the event of organization trying to reengineer some business process, they will normally identify the section of the business that is inefficient. This is normally done by interviewing various stakeholders of that organization. For example in a hospital, the doctors, nurses, health assistants, clerks, and the patients can be survey and interview on their opinion with respect to that inefficiencies identify in the process of reengineering. The stakeholders in the organization can be found by querying the ontology for the decision makers and checking the ontology map to find the particular actors playing the role of decision makers.

\subsection{Update This Business Process In The Organizational Ontology}

The business process gaps identified in section 6 are then evaluated by the team undertaking the business process reengineering process. They will therefore determine how the business process or the environment will be address to handle these inconsistencies. This solution can be either giving enough training to the employee of the organization or outsourcing some information systems artifact that can help the organization do business in a more efficient easy.

\section{CONCLUSION AND FUTURE WORK}

In this paper we proposed a methodology based on organizational ontology development. Some techniques that includes knowledge map, business process models and organizational ontology. It was found that for successful business reengineering process to be achieved, the team has to consider the environment where the programme is taking place. The success of this proposed methodology is strictly depending on the quality of the knowledge source map and structure map. Only if the stakeholders of the organizational have the full knowledge of the task and sub task of the organization, a quality knowledge map will be difficult to achieved.

This finding is too general as we did not specify any area of case study, in future there is need to instantiate the methodology using ontology modeling languages like protégé OWL to validate the methodology in a particular domain like health care organization.

\section{REFERENCES}

[1] Yasin Ozcelik, 2007, Do business process reengineering projects payoff? Evidence from the United States, International Journal of Project Management 28, 7-13

[2] E. Yu, J. Mylopoulus, 1993, Organization modelling for business processes reengineering, in: W. Hamscher (Ed.), Working Notes of the AAAI- workshop on Artificial

[3] M. Hammer, J. Champy, Reengineering the Corporation: A Manifesto for Business Revolution, Nicholas Brealey Publishing, London, U.K.,.

[4] Martinez EV, 1995, Successful reengineering demands IS/business partnerships. Sloan Manage Rev ;36(4):51-60.

[5] Lila Rao, 2012, Building ontology based knowledge maps to assist business process re-engineering, Decision Support Systems 52, 577-589 
Computer Science \& Engineering: An International Journal (CSEIJ), Vol. 3, No. 6, December 2013

[6] Yasin Ozcelik, 2010, Do business process reengineering projects payoff? Evidence from the United States, International Journal of Project Management 34 9-24

[7] Hammer M, Champy J., 1993,Reengineering the corporation. A Manifesto for business revolution. New York, NY: Harper Business Press;

[8] Martinez EV., 1995, Successful reengineering demands IS/business partnerships. Sloan Manage Rev ;36(4):51-60..

[9] J Moul, 1995 Does reengineering really works? Datamation, page 22-28

[10] Hales, H. L., \& Savoie, B. J. (1994, September). Building a foundation for successful business process reengineering. Industrial Engineering 26(9), 17-19.

[11] Farmer J.R. 2009. 'Re-engineering the factory'. Production and Inventory Management Journal, 34(1): 38-42.

[12] De Bruyn B and Gelders L. 1997. 'From TQM to BPR: Two case studies in personnel administration'. International Journal of Production Economics, 50(2-3): 169-181.

[13] Sharp J.M, Irani Z and Klein M.M. 1993. 'IEs fill facilitator role in benchamrking operations to improve performance'. Industrial Engineering, 25(9): 40-43.

[14] Manganelli R.L and Klein M.M. 1994. 'The re-engineering handbook: A step-by-step guide to business transformation' AMACOM, New york, USA.

[15] Hammer M and Champy J. 1993. 'Re-engineering the corporation: A Manifesto for business revolution'. Harper Colllins, New York, USA.

[16] Swart J and Powell JH (2006) Men and measures: capturing knowledge requirements in firms through qualitative system modelling. Journal of Operational Research Society 57(1), 10-21.

[17] Kwan M And Balasubramanian P (2003) KnowledgeScope: managing knowledge in context.Decision Support Systems 35(4), 467-486.

[18] Brandon DP and Hollingshead Ab (2004) Transactive memory systems in organizations: matching, tasks, expertise, and people. Organization Science 15(6), 633-644.

[19] Kishore R, Zhang H And Ramesh R (2006) Enterprise integration using the agent paradigm: foundations of multi-agent-based integrative business information systems. Decision Support Systems 42(1), 48-78.

[20] Martin J. Eppler, 2008 A Process-Based Classification of Knowledge Maps and Application Examples, Knowledge and Process Management Volume 15 Number 1 pp 59-71 (2008)

[21] Kishore R, Zhang $H$ And Ramesh R (2006) Enterprise integration using the agent paradigm:foundations of multi-agent-based integrative business information systems. Decision Support Systems 42(1), 48-78.

[22] Fox Ms, Barbuceanu M, Gruninger M And Lin J (1998) An organisation ontology for enterprise modeling. In Simulating Organizations: Computational Models of Institutions and Groups (Prietula M, Carley K And Gasser L, Eds), pp 131-152, AAAI/MIT Press, Menlo Park, CA

\section{Authors Profile}

Mahdi Alhaji Musa is currently a PhD Student of Information Systems at Faculty of Computing, Universiti Teknologi Malaysia (UTM). Mahdi holds M.Sc in Information Technology from UTM, and B.Eng. in Electrical Engineering from Bayero University Kano, Nigeria. His main research interests are E-learning, M-learning, Innovative Solutions for "knowledge-based", BPR, Information Systems that span several areas applying ontology and Knowledge management for interoperating Information Systems, Computer Networks, IPV6.Science and Information Systems,Universiti Teknologi Malaysia (UTM)

Mohd Shahizan Othman received his BSc in Computer Science with Specialization in Information Systems from Universiti Teknologi Malaysia Malaysia, in 1998. Then he proceeds to Universiti Kebangsaan Malaysia (UKM) where he obtained his Msc in Information Technology. Shahizan holds a PhD from UKM in Web Information Extract Information Retrieval and Machine Learning. He is currently a senior lecturer at the Faculty of Computer Science and Information Systems, UTM. His research interests are

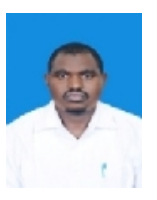
Information extraction, Information retrieval on the web, web data mining, content management and machine learning. 
Computer Science \& Engineering: An International Journal (CSEIJ), Vol. 3, No. 6, December 2013

Waleed Mugahed Ali AL-Rahmi, received his BSc in in the Marine Science Telecommunication in Yemen, in 2002 .Then he earned Diploma in Computer Information coding from the Department of Electronics and Computer Systems in Yemen in 2005. After, then he earned a Diploma Of Computer Science from the National Institute of Administrative Sciences in Yemen in 2007 .He studied five levels in the

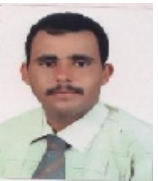
English language in Malaysia in 2010 . He is finshed the master degree from Universiti Teknologi Malaysia in 2011.He is currently a graduate student (Ph D)at the Faculty of Computer 